\title{
The Effect of Submerged Aquatic Vegetation Expansion on a Declining Turbidity Trend in the Sacramento-San Joaquin River Delta
}

\author{
Erin Lee Hestir ${ }^{1,2}$ (D) David H. Schoellhamer ${ }^{3,4}$ - Jonathan Greenberg ${ }^{2,5}$. \\ Tara Morgan-King ${ }^{4}$ - Susan L. Ustin ${ }^{2}$
}

Received: 11 February 2015 / Revised: 6 November 2015 / Accepted: 21 November 2015 / Published online: 1 December 2015

(C) The Author(s) 2015. This article is published with open access at Springerlink.com

\begin{abstract}
Submerged aquatic vegetation (SAV) has welldocumented effects on water clarity. SAV beds can slow water movement and reduce bed shear stress, promoting sedimentation and reducing suspension. However, estuaries have multiple controls on turbidity that make it difficult to determine the effect of SAV on water clarity. In this study, we investigated the effect of primarily invasive SAV expansion on a concomitant decline in turbidity in the Sacramento-San Joaquin River Delta. The objective of this study was to separate the effects of decreasing sediment supply from the watershed from increasing SAV cover to determine the effect of SAV on the declining turbidity trend. SAV cover was determined by airborne hyperspectral remote sensing and turbidity data from longterm monitoring records. The turbidity trends were corrected for the declining sediment supply using suspended-sediment concentration data from a station immediately upstream of the Delta. We found a significant negative trend in turbidity from 1975 to 2008, and when we removed the sediment supply
\end{abstract}

Communicated by Carl T. Friedrichs

Erin Lee Hestir

elhestir@ncsu.edu

1 Marine, Earth, and Atmospheric Sciences, North Carolina State University, Raleigh, NC 27695, USA

2 Center for Spatial Technologies and Remote Sensing, University of California, Davis, CA 95616, USA

3 Department of Civil and Environmental Engineering, University of California, Davis, CA 95616, USA

4 California Water Science Center, United States Geological Survey, Sacramento, CA 95819, USA

5 Geography and GI Science, University of Illinois at Urbana-Champaign, Champaign, IL 61820, USA signal from the trend it was still significant and negative, indicating that a factor other than sediment supply was responsible for part of the turbidity decline. Turbidity monitoring stations with high rates of SAV expansion had steeper and more significant turbidity trends than those with low SAV cover. Our findings suggest that SAV is an important (but not sole) factor in the turbidity decline, and we estimate that $21-70 \%$ of the total declining turbidity trend is due to SAV expansion.

Keywords Submerged aquatic vegetation (SAV) - Turbidity . Suspended sediment $\cdot$ San Francisco Estuary

\section{Introduction}

Submerged aquatic vegetation (SAV) has well-documented effects on water clarity (Crooks 2002; Madsen et al. 2001). Where SAV beds are established, they can slow water movement and reduce bed shear stress, which promotes sedimentation and increases bed material retention (Boer 2007; Champion and Tanner 2000; Liu et al. 2013; Sand-Jensen and Mebus 1996). This can reduce water turbidity caused by suspended materials. SAV also impacts water clarity by reducing phytoplankton biomass through allelopathy (Vanderstukken et al. 2014), competition (Sand-Jensen and Borum 1991), or by facilitating grazers (Scheffer et al. 1993). Because light availability is a critical limiting factor for SAV establishment and growth (Dennison et al. 1993; Moore et al. 2012), SAV is often described as an ecosystem engineer (Crooks 2002). Although the interaction between SAV and turbidity are complex, they are often described as a positive feedback loop: as light availability increases, plant growth is promoted, which can further reduce turbidity (Madsen et al. 2001; Scheffer and van Ness 2007). 
In estuaries, SAV turbidity feedback loops are complicated by the multiple factors that control turbidity, including strong top-down control of phytoplankton by benthic suspension feeders, high mineral contribution to turbidity, and variations in turbidity due to watershed (upstream) and coastal (downstream) inputs, tidal fluctuations, and short residence times (Jassby et al. 2002). In coastal and estuarine systems, SAV changes have been associated with both phytoplankton growth (Orth et al. 2006; Waycott et al. 2009) and suspended sediment (Findlay et al. 2014; Moore et al. 2012). Estuaries are also characterized by high hydrodynamic and sediment variability, and SAV beds have variable spatial distribution and density across an estuary, which results in variable influences on settling and resuspension dynamics (Madsen et al. 2001). This can complicate identifying potential feedbacks and quantifying the effect of SAV on water clarity. While SAV beds in estuaries have been shown to have a local effect on turbidity (Findlay et al. 2014), determining the systemwide effect remains a challenge.

The Sacramento-San Joaquin River Delta (the "Delta") is the upstream component of the San Francisco Estuary. The San Francisco Estuary is a highly urbanized estuary with a long history of human modification to sediment supply and high rates of biological invasions (Cloern and Jassby 2012). Water optical properties in the Delta, as in most estuaries, are primarily explained by suspended minerals (Cloern 2001; Jassby et al. 2002). Over the past decades, water clarity in the Delta has increased as suspended matter has decreased (Cloern and Jassby 2012; Jassby et al. 2002; Hestir et al. 2013). Declining sediment supply is thought to be the primary driver of increasing water clarity in the Delta (Wright and Schoellhamer 2004). However, there is one current sedimentation model for the system that accounts for the role of SAV explicitly by incorporating a positive SAV turbidity feedback loop (Schoellhamer et al. 2012). In this model, SAV beds filter suspended sediments out of the water and clear, filtered water is exported out of the beds by tidal action, thus reducing turbidity in other locations (Schoellhamer et al. 2012). Currently, the model assumes SAV is not an important factor in the open water modules, only the relatively small components of the littoral zones. However, SAV has been expanding into the open waters of the Delta over the past several decades, and its role in reducing turbidity may be underestimated.

Remote sensing and spatially distributed long-term monitoring networks potentially provide the sampling required to represent the range of conditions that occur in an estuary and may provide the data needed to quantify the effect of SAV on turbidity at the estuary scale. The objective of this study was to separate and determine the effects of SAV abundance on turbidity in an estuary which has had decreasing turbidity over the past three decades. Two events have occurred that may explain the decrease in turbidity: (1) invasion and rapid expansion of SAV and
(2) decreased sediment supply (Hestir et al. 2013; Schoellhamer et al. 2013).

To estimate the contribution of SAV to the turbidity decline, we used trends in SAV cover determined by remote sensing and turbidity data from long-term monitoring records from the Delta. We considered sediment supply from the watershed to the external (upstream) factor controlling turbidity trends in the Delta. By removing the sediment supply variable and examining the resulting turbidity trend, we could estimate the internal (in-stream) factors that control turbidity, primarily sediment settling and resuspension. Because turbidity is primarily explained by suspended minerals, and SAV presence and density plays a critical role in controlling settling and resuspension, we could use SAV cover measurements and sediment supply-adjusted turbidity trends to estimate the effect of SAV on the turbidity trends in the Delta.

\section{The Delta: A Highly Modified Ecologically Impaired Estuary}

The Delta drains over $160,000 \mathrm{~km}^{2}$ into the Pacific Ocean via the San Francisco Bay (Fig. 1). The Delta is a tidal river network of levee-bound channels, rivers, and flooded tracts of lands (or lakes) that comprise the upstream component of the San Francisco Estuary, the largest estuary in the Western USA. The hydrodynamic heterogeneity of the estuary is manifest in a wide range of salinity, tidal fluxes, and seasonal and interannual freshwater inflows that reflect the Mediterranean climate and precipitation patterns of California. The annual dry season occurs in late spring through early fall; precipitation and the bulk of runoff occurs in the winter and early spring. Freshwater inflows average $1700 \pm 300 \mathrm{~m}^{3} \mathrm{~s}^{-1}$ in the winter and $540 \pm 40 \mathrm{~m}^{3} \mathrm{~s}^{-1}$ in the dry season (SE for years 1968-1995, Jassby and Cloern 2000), with extreme interannual variation. The Sacramento River (the largest in California) is the main tributary to the Delta and the primary source of inflow and sediment to the Delta (Wright and Schoellhamer 2005)

The Delta has semi-diurnal tides but supplies water to much of California and thus is mostly managed as an annual freshwater system by upstream dam releases from the Sacramento River, San Joaquin River, and their tributaries. Some flow is routed across the Delta through a series of channels, seasonal barriers, and gates to the export pumps of the State and Central Valley Water Projects in the south Delta. This infrastructure can divert $30 \%$ of the Sacramento River flows into the Delta during the wet season and nearly $60 \%$ in the dry season (Nichols et al. 1986). It provides drinking water for 22 million people and supplies water to support a significant part of California's $\$ 42.6$ billion agricultural industry (CDFA 2013). Additionally, the Delta is critical habitat to several threatened and endangered species. 


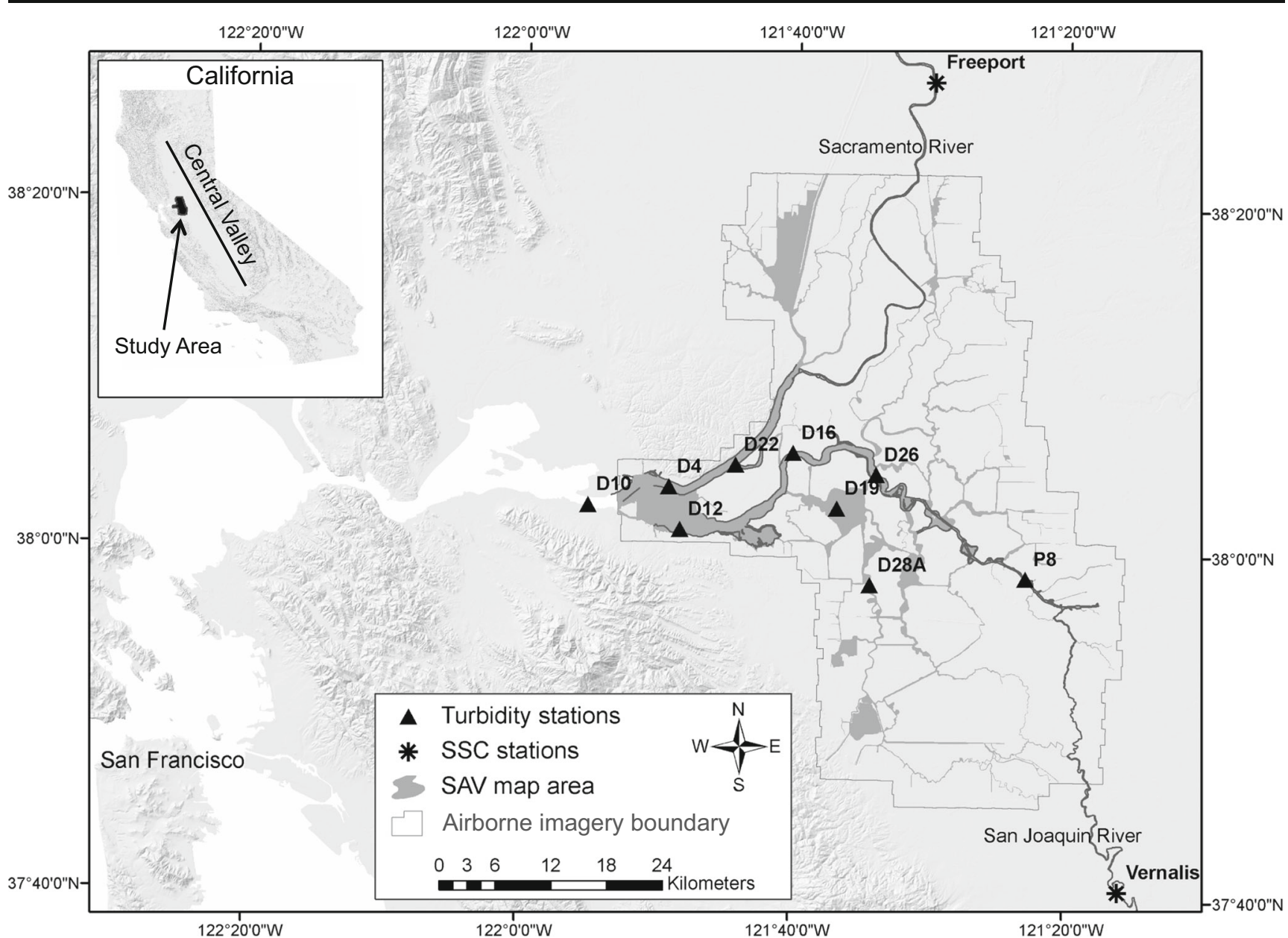

Fig. 1 The upper San Francisco Estuary, including the Sacramento-San Joaquin River Delta. The waterways where submerged aquatic vegetation (SAV) was mapped are shaded dark grey. Monthly turbidity monitoring

In the Delta, turbidity has become one of the focal water quality indicators for the endangered Delta smelt (Hypomesus transpacificus). Since 2000, the abundances of four key pelagic fish species, including the Delta smelt, have declined precipitously (Sommer et al. 2007). Reduced turbidity has been identified as one of the critical contributors (Feyrer et al. 2007; Sommer and Meja 2013). Delta smelt are dependent on highly turbid water (18 Nephelometric Turbidity Units (NTU)) for successful feeding (Baskerville-Bridges et al. 2004; Sommer and Meja 2013), and their habitat use is directly linked to regions in the Delta with higher turbidities $(>12$ NTU, Nobriga et al. 2005; Feyrer et al. 2007). Thus, the declining turbidity trends are a concern for Delta smelt habitat condition. Additionally, increasing water clarity, changing inflows, and the invasion of the invasive clam Corbula amurensis in the estuary has contributed to a long-term but regionally variable decline in phytoplankton (Jassby 2008) and a shift in phytoplankton species composition, timing, and variability of primary production (Jassby et al. 2002). These changes have raised serious concerns about the stability stations are represented by black triangles, and suspended sediment concentration (SSC) stations are designated by stars

of the food web and the importance of nutrient inputs in a traditionally light-limited estuary (Cloern and Jassby 2012).

Increasing water clarity in the Delta is thought to be primarily the result of the long-term impacts of anthropogenic disturbance in the estuary's watershed (Schoellhamer et al. 2013). After an initial sediment pulse due to deforestation, hydraulic mining, and agricultural and urban development, suspended sediment supply to the Delta is now decreasing due to dams, diversions, and bank protection (Schoellhamer et al. 2013). Suspended sediment supply decreased nearly $50 \%$ from 1957 to 2001 (Wright and Schoellhamer 2004), and there were significant step decreases of total suspended solid (TSS) concentrations in the Delta of $27 \%$ in 1983 and $23 \%$ in 1998 (Hestir et al. 2013; Schoellhamer et al. 2013).

The SAV expansion is dominated by invasion of Egeria densa (Santos et al. 2011), which occurs in 59-64 \% of SAV species surveys (Ustin et al. 2014) and contributes $85 \%$ of the SAV community biomass as of 2010 (Hestir et al., unpublished data). Described as an ecosystem engineer (Crooks 2002), E. densa has been actively changing aquatic habitat 
in the Delta (Ferrari et al. 2014; Santos et al. 2009; Service 2007). E. densa beds have thick branching and intertwining stems that form dense mats at the water surface during peak growth and slow water speed (Champion and Tanner 2000). In the Delta, E. densa most commonly co-occurs with native Ceratophyllum demersum and nonnative Myriophyllum spicatum but has a negative effect on the presence of M. spicatum as well as nonnative Potamogeton crispus and native Elodea candensis (Santos et al. 2011).

SAV occurrence in the Delta is determined not only by light availability but also variable water depth, substrate type, and water velocity (Hestir 2010; Marineau 2015; Santos et al. 2011). It is unlikely that SAV is limited by nutrient availability or freezing temperatures because the Delta has high nutrient availability (Jassby and Cloern 2000) and relatively warm water temperatures throughout the year (Lucas et al. 2002), providing generally favorable habitat for SAV. SAV occurrence was first recorded in the 1960s, when SAV cover was minimal. By the 1990s, SAV expanded to nuisance levels in the Delta (Brown and Michniuk 2007; Jassby and Cloern 2000). The nonnative SAV species in the Delta have several competitive adaptations that have facilitated their invasion, but the exact causes are unknown. Nonnative SAV (most notably, E. densa) has two growth peaks, one in summer and one in late fall, and can successfully overwinter, maintaining a large portion of biomass from year to year (Santos et al. 2011). This provides a competitive edge over native species persistence. Further, Santos et al. (2012) found that all nonnative SAV species in the Delta have both $\mathrm{C}_{3}$ - and $\mathrm{C}_{4}$-like photosynthetic pathways, allowing them to photosynthesize at high solar radiation levels at the surface and low radiation levels at greater water depths. This adaptation not only allowed nonnative species to establish in the same environments as native species and to colonize both highly turbid areas and areas with high light and temperature conditions of shallow and tidal sites (Santos et al. 2012). Ustin et al. (2014) postulate that the combination of declining sediment supply coupled with the competitive advantage of nonnative species could have triggered the rapid SAV expansion; however, this has not been studied in depth.

\section{Methods}

\section{Turbidity Data}

Turbidity (Nephelometric) was measured monthly $1 \mathrm{~m}$ below the surface by the Bay Delta Environmental Monitoring Program (EMP). Turbidity was measured using Hach 2100 A, 2100 P, or YSI 6136 turbidimeters. Routine testing, maintenance, and calibration of field equipment were performed before and after each sampling run. The maximum deviation allowed for instrument calibration was $3 \%$. The EMP considers all measurements to be comparable. Additional information about the EMP program and sampling details can be found at http://www.water.ca.gov/bdma/meta/discrete. cfm.

There were eight sites in the Delta that were monitored from 1975 to 2008 and were within the SAV mapping area (Fig. 1). A ninth site, D10, is west of the SAV mapping area but was included in the trend analysis.

\section{River Sediment Data}

The US Geological Survey reports suspended solid concentration (SSC) and suspended sediment discharge in the Sacramento River at Freeport (site 1147650) and on the San Joaquin River at Vernalis (site 11303500) (Fig. 1). We used the daily average reported value for this study (http:// waterdata.usgs.gov/nwis). The Freeport station began operation in 1979. Although the data were collected at a station upstream from 1975 to 1978 , data from the two stations are considered equivalent (Wright and Schoellhamer 2004).

\section{Turbidity Trend Test}

We used the Seasonal Kendall test, a nonparametric method used to identify monotonic directional trends in water quality data that accounts for seasonal variability (Helsel and Hirsch 1992) to determine whether there was a decreasing turbidity trend in the Delta. Trend rates were calculated using the TheilSen slope estimator. The tests were implemented in the ESTREND program (Schertz et al. 1991) for SPlus (TIBCO Spotfire S+ 8.1) (http://bwtst.usgs.gov/apps/s-plus/index. $\mathrm{html})$. We considered a trend to be significant if $p<0.05$. We applied the trend test to the measured turbidity records, and the trend test was also applied to turbidity data corrected for sediment supply. For the San Francisco Estuary, SSC and turbidity are strongly linearly correlated (Ganju et al. 2007; Schoellhamer et al. 2007, 2012). Thus, we considered trends of turbidity and SSC in units of percent mean value per year to be comparable.

We applied linear regression to the log-transformed 5-day mean flow and SSC at Freeport, which smoothed the effect of variable water flow on the SSC data. For the sediment supply correction, we used the mean SSC at Freeport for the 5 days prior to collection of the turbidity sample. A 5-day mean was used as travel time from the Sacramento River into the Delta, based on estimates from Kuivila and Foe (1995). At each turbidity site in the Delta, we applied linear regression to the log-transformed turbidity and to the residuals from SSC measured at Freeport. We then applied the Seasonal Kendall test to the residual turbidity to determine the sediment supply corrected trend. 


\section{SAV Distribution}

We used SAV maps from (Hestir et al. 2012) to measure SAV cover distribution from 2004 to 2008 and conducted a review of previous field surveys and reports to infer historical distribution. The SAV maps were made from airborne imaging spectroscopy collected annually in over a 2 -week period in June and July 2004-2008 with the HyMap sensor (Cocks et al. 1998) flown at an altitude of $1500 \mathrm{~m}$. A total of $2166 \mathrm{~km}^{2}$ was covered by 48 flight lines each year for 5 years. The HyMap sensor measures reflected energy in 126 spectral channels across the visible-to-shortwave-infrared regions of the spectrum (450-2500 nm). We applied an ensemble classification tree algorithm to map SAV, emergent and floating vegetation, and open water absence of any vegetation from the imagery. Over 7500 field locations were recorded from 2004 to 2008 and were used to train and independently validate the algorithm. Field observations from propeller motor boats and airboats were made concurrent with the overflights. Field crews recorded GPS location ( $<1 \mathrm{~m}$ accuracy), cover class, percent cover, approximate dimensions of the patch, water depth above the canopy (for SAV), and Secchi disk depth (for SAV and water locations) (Hestir et al. 2012).

The resulting maps have a ground resolution of $3 \mathrm{~m} \times 3 \mathrm{~m}$ $\left(9 \mathrm{~m}^{2}\right)$, and the overall mapping accuracies for each year range from 79 to $85 \%$. The producer's and user's accuracies detail the error of omission and commission (respectively) and are summarized in Table 1. Water depth above the SAV canopy and turbidity did not significantly affect the classification accuracy. The Kappa statistic, which can range from 0 to 1 , is an indicator of the level of agreement between ground data and map results that accounts for the probability of random agreement. For the SAV map class, the Kappa was $0.71-0.83$, indicating very good agreement with independent field observations (Monserud and Leemans 1992) (Table 1). Table 1 summarizes the image acquisition dates and mapping accuracies. Details about the SAV mapping can be found in Hestir et al. (2012). SAV classification images were exported to shapefiles for subsequent analysis in a geographic information system (GIS).
We estimated that the local, or bed effect, of SAV would be over a distance wherein the time it takes a particle to settle from the surface to the bottom is of the same order of magnitude as the time it takes a parcel of water to move through a given distance. Assuming average particle settling velocities were approximately $0.001 \mathrm{~m} \mathrm{~s}^{-1}$, average depth was $5 \mathrm{~m}$, and average water velocity was $0.3 \mathrm{~m} \mathrm{~s}^{-1}$, the SAV bed effects would be over approximately $1 \mathrm{~km}$. Thus, we generated a 1 $\mathrm{km}$ radius boundary around each long-term turbidity monitoring station using ArcMap 9.2 (ESRI, Redlands, CA) and calculated the percent cover of SAV as the fraction of the total area of waterway (as defined by the US Bureau of Reclamation waterways GIS layer) from the within the $1-\mathrm{km}$ radius (Fig. 2).

We calculated the average SAV cover from 2004 to 2008 within each of the turbidity sites in order to minimize the influence of year-to-year fluctuations in SAV cover, even though these were minimal. Using ANOVA, we found no significant difference in SAV cover between years in the $1-\mathrm{km}$ radius boundaries $(F=1.38$, $p=0.24)$. We used the average cover of 2004-2008 as an estimate of the contemporary SAV cover at the turbidity monitoring stations.

Given that the methods of estimating SAV cover are different from study to study (e.g., field observations versus remote sensing measurements), we made the general assumption of a linear increase between 1975 and 2008, where cover started at zero in the 1970s and was maximum from 2004 to 2008 .

\section{Estimating the Effects of SAV on the Turbidity Trend}

We estimated the effect of SAV expansion on the turbidity trend by calculating the portion of the trend attributable to SAV as a function of SAV cover. We only estimated this effect for sites that had significant trends. We used two approaches to provide upper and lower bounds on the effect of SAV expansion on the turbidity trend. The lower bound provides a conservative estimate of the SAV effect. For the lower bound, we assumed that the trend in river sediment supply is equal to

Table 1 Image acquisition dates and mapping accuracies for SAV distribution maps

\begin{tabular}{|c|c|c|c|c|c|}
\hline Image acquisition & $\begin{array}{l}\text { Overall } \\
\text { accuracy }\end{array}$ & $\begin{array}{l}\text { Overall } \\
\text { kappa }\end{array}$ & $\begin{array}{l}\text { Kappa submerged } \\
\text { vegetation }\end{array}$ & $\begin{array}{l}\text { Producer's accuracy } \\
\text { submerged vegetation }\end{array}$ & $\begin{array}{l}\text { User's accuracy } \\
\text { submerged vegetation }\end{array}$ \\
\hline 25 June 25 2004-10 July 102004 & $78.8 \%$ & 0.65 & 0.83 & $64.7 \%$ & $89.5 \%$ \\
\hline 22 June 2005-8 July 2005 & $84.3 \%$ & 0.70 & 0.79 & $80.0 \%$ & $86.7 \%$ \\
\hline 21 June 2006-26 June 2006 & $85.9 \%$ & 0.77 & 0.83 & $82.4 \%$ & $90.9 \%$ \\
\hline 19 June 2007-26 June 2007 & $79.6 \%$ & 0.69 & 0.71 & $72.2 \%$ & $80.5 \%$ \\
\hline 29 June 2008-7 July 2008 & $84.6 \%$ & 0.69 & 0.54 & $55.8 \%$ & $60.6 \%$ \\
\hline
\end{tabular}

For details about image classification and performance see Hestir et al. (2012) 

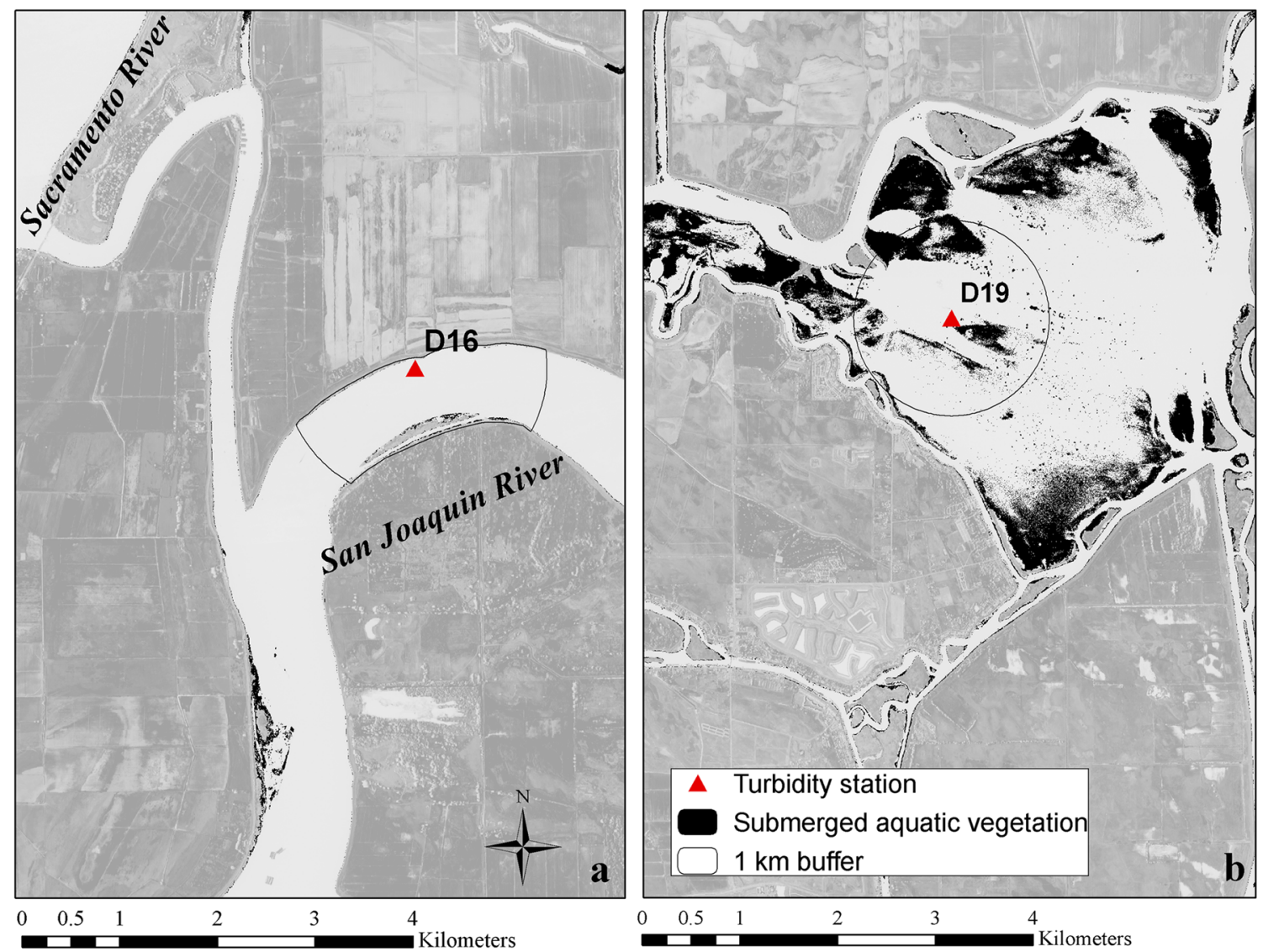

Fig. 2 A close-up view of the SAV cover around two turbidity stations, D16 and D19. The SAV is mapped in black and the turbidity sampling station is indicated by the red triangle. The 1-km radius buffer within the water around the station is indicated by the black lines surrounding the turbidity stations

the turbidity trend. If the turbidity trend was weaker than the sediment supply trend, we assumed the effect of SAV was zero. This assumption overestimates the effect of river sediment supply and underestimates the effect of SAV by assuming that river waters do not pass through SAV beds and mix with water in the Delta.

The upper bound, or liberal estimate of the SAV effect, assumes that the sediment supply-adjusted turbidity trend is due entirely to SAV. This assumption overestimates the effect of SAV expansion because there are likely other factors contributing to variations in Delta turbidity, such as phytoplankton and other organic matter.

\section{Results}

\section{Turbidity Trend Without Sediment Supply Adjustment}

Turbidity in the Delta had a significant declining trend at eight of nine sites from 1975 to 2008 (Table 2). The only site without a significant trend was D22, on the Sacramento River upstream from the Sacramento-San
Joaquin River confluence, which had a decreasing trend but did not meet our threshold of significance with a slightly higher $p$ value ( $p=0.06)$ (Fig. 3). At the sites with a significant downward trend, the slope ranged from -1.1 to $-2.3 \%$ of the mean site turbidity per year.

\section{River Sediment Supply Trend with and Without Flow Adjustment}

Flow correction proved to be necessary for detecting a significant downward trend of SSC in the Sacramento River with the Seasonal Kendall test. The 5-day mean SSC had a downward trend with $p=0.06$. When SSC was corrected for the 5-day mean discharge, there was a significant downward trend of $-1.3 \%$ of the mean SSC per year $(p<0.01)$. The $r^{2}$ of the regression between log-transformed 5-day mean SSC and discharge was 0.56 .

The 5-day mean SSC in the San Joaquin River also had a significant downward trend of $-1.3 \%$ of the mean SSC per year $(p<0.001)$. However, flow and SSC were poorly correlated in this river $\left(r^{2}<0.01\right)$; therefore, flow correction had a negligible effect on trend. 


\section{Turbidity Trend Adjusted for Sediment Supply}

When turbidity was corrected for sediment supply, the strength and statistical significance of the trend decreased relative to the uncorrected turbidity data. After adjusting for sediment supply, most sites still had a significant downward trend ranging from -0.83 to $-2.07 \%$ of the mean turbidity per year (Table 2). The two sites in the Sacramento River (D22 and D4) and one site just downstream from the confluence of the Sacramento and San Joaquin Rivers (D10) did not have a significant trend after supply adjustment.

\section{The Effect of SAV on the Turbidity Trend}

Stations with high rates of SAV expansion had steeper and more significant decreasing turbidity trends (Table 2). Among those sites with a significant trend, the average trend in decreased turbidity unadjusted for sediment supply was $-1.6 \% /$ year of the mean site turbidity per year and the average decreasing trend when adjusted for sediment supply was $-1.3 \%$ of mean site turbidity per year. These decreasing trends correspond to an observed expansion of SAV from little or no cover at the beginning of the time series (1975) to its current distribution, covering approximately $6 \%$ of the water surface at turbidity stations.

The conservative estimate for the SAV expansion effect on the turbidity trend ranged from zero effect to $44 \%$, whereas the liberal estimates of SAV effect ranged from 40 to $100 \%$ (Fig. 4). The mean of the lower and upper estimates was $21-$ $70 \%$. The effect of SAV expansion on the turbidity trend varied with SAV cover, but generally the effect increases as SAV cover increases. There is a distinct difference in effect estimates between sites with low versus high SAV cover (Fig. 4). The two sites with the highest SAV had the greatest effect on the turbidity trend. These two sites were located in Frank's Tract, a large shallow lake in the Central Delta created by the flooding of an agricultural tract after levee breaches in the late 1930s (D19), and in Old River, a former channel of the San Joaquin River in the southwestern delta (D28A). The lower bounds of the effect estimates at these sites (39 and $44 \%$ ) are close to or greater than to the upper bound estimates at low cover sites (40-56 \%; Fig. 4).

\section{Discussion}

\section{Decreasing Turbidity Trends Attributable to SAV Expansion}

The observed trends in Sacramento River SSC and turbidity in the Delta support findings from previous studies that observed significant declines in turbidity and sediment in this system. Wright and Schoellhamer (2004) found that the sediment yield 


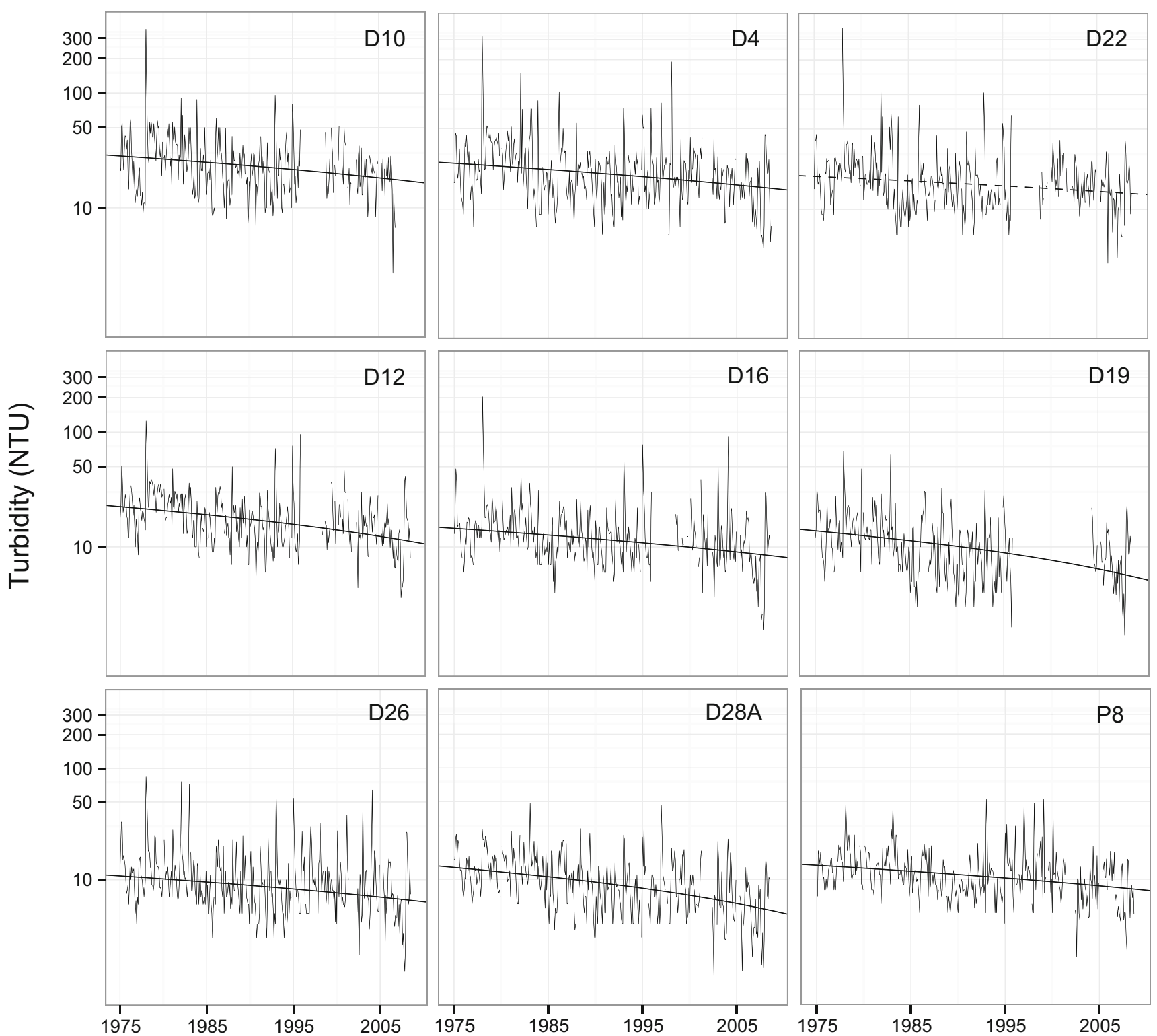

Fig. 3 Monthly turbidity measured nine monitoring stations in the Delta (see Fig. 1 for station location information) from 1975 to 2008. The TheilSen slope is plotted for each site. See Table 2 for slope estimates and trend statistics. There was no significant trend for site D22, thus the slope is

indicated with a dashed line. Gaps in the time series (blank regions) are periods when data were not collected. Note turbidity (in NTU) is displayed on log-scale on the y-axes

of the Sacramento River decreased by about one half from 1957 to 2001 and the trend was $-1.1 \%$ of the mean value per year. This is similar to the $-1.3 \% /$ year trend found for 1975-2008 in this study. Unlike the Sacramento River, the San Joaquin River watershed did not experience hydraulic mining, but it is just as regulated and impounded as the Sacramento River, which may account for the similarity in the declining SSC trends. Jassby et al. (2002) analyzed TSS concentration data from many of the same sites used in this study and also found a $50 \%$ decrease from 1975 to 1995 . They found a TSS trend of $-2.4 \% /$ year which is near the upper limit of turbidity trends found in this study (Table 2).
This is the first study in the Delta to examine turbidity trends with the supply signal removed, and our findings indicate that SAV expansion may have contributed to the observed increase in water clarity.

Sites with high SAV cover had stronger, more significant turbidity trends. This pattern was most notable for the sediment supply-adjusted turbidity trends. When the sediment supply signal was removed from the trend analysis, significant decreasing trends were still identified at six of the nine sites. Of the three sites that did not have a significant trend after supply adjustment, two had information available about associated SAV cover (D22 and D4 both in the Sacramento River), 


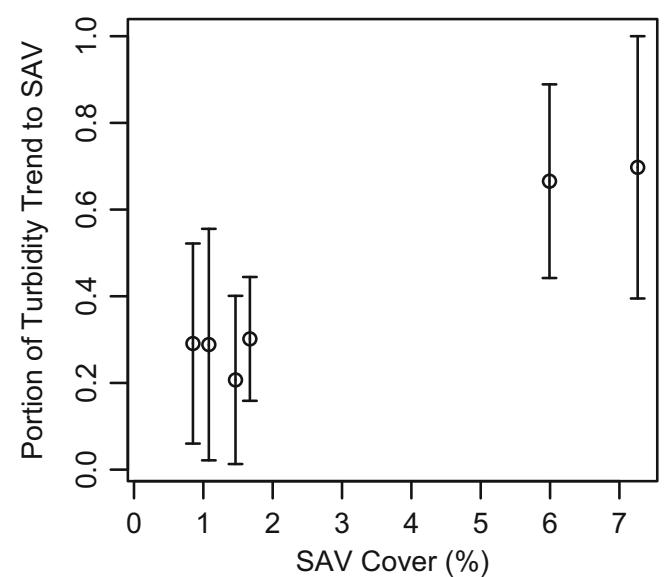

Fig. 4 The portion of the decreasing turbidity trend attributable to submerged aquatic vegetation (SAV) as a function of SAV cover at sites with significant supply-adjusted trends. The lower bound assumes that the trend in river sediment supply is equal to the supply turbidity trend, overestimating the effect of river supply and underestimating the effect of SAV. The upper bound assumes that the turbidity trend adjusted for sediment supply is due entirely to SAV, overestimating the effect of SAV on the trend. The mean of these two estimates is represented by circles

and SAV cover in these sites was lower than the average cover of all the sites. The two sites with the strongest decreasing turbidity trend, D28A in Old River and D19 in Frank's Tract, had higher SAV cover than the other sites. Although there was higher SAV cover at D28A than at D19, the unadjusted turbidity trend was stronger at D19 than D28A. However, when the turbidity trend was adjusted for sediment supply, the strength of the trend between sites switched: D28A, which had higher cover, had a larger trend than D19. These results indicate that SAV cover likely had an effect on the decreasing turbidity trend. However, these sites are also nearer to the San Joaquin River, yet we adjusted for sediment supply using the Sacramento River. Thus, there could be an overestimation in SAV contribution at these sites.

\section{Changing Sediment Supply Regimes and SAV Interactions: Upstream Versus in-Stream Influences}

TSS concentrations in the Delta were significantly trending downward from 1975 to 1983 (Hestir et al. 2013). After the 1982-1983 El Niño storms, there was record-high discharge during the winter season and the following summer season from dam releases intended to reduce the volume of the filled reservoirs. The combined events of high winter discharges coupled with higher summer discharges of clear waters "flushed" much of the erodible sediment pool from the Delta, resulting in a significant step decrease in Delta TSS in 1983 (Hestir et al. 2013). After the 1983 step decrease, there was no trend in TSS until another significant step decrease in 1998 following the 1997-1998 El Niño storms. After the 1998 step decrease, there was a significant decreasing trend in TSS from 1998 to 2010 (Hestir et al. 2013).

It is likely that the initial sediment flushing following the 1982-1983 El Niño storms shifted the Delta into a less turbid state that may have favored the initial SAV expansion, explaining the accelerated invasion observed between 1982 and 1999 (Brown and Michniuk 2007; Jassby and Cloern 2000; Nobriga et al. 2005; Schoellhamer et al. 2013). The decreasing TSS trend in the 2000s following the 1997-1998 El Niño storms has been attributed to a shift from transport to supply regulation (Hestir et al. 2013; Schoellhamer 2011) following reductions of sediment supply from the watershed and a flushing of the erodible sediment pool within the estuary. However, the declining TSS trend of the 2000s has also been attributed to sediment trapping by SAV, where SAV functions as a sediment filter (Schoellhamer et al. 2012, 2013). Our study supports Schoellhamer et al. (2013), providing some evidence for the effect of SAV on declining turbidity.

Our approach addressed the upstream (sediment supply) and in-stream (supply-adjusted turbidity trend) factors controlling turbidity trends. One factor we did not consider in this analysis is the interaction of the Delta and the San Francisco Bay, the downstream variable. Tides exchange water and suspended sediment between the Bay and Delta, and a decrease in Bay SSC would decrease SSC in the western Delta within several kilometers (one tidal excursion) of the Bay. SSC in the Bay decreased by $36 \%$ from 1991to 1998 and from 1999 to 2007 (Schoellhamer 2011). The SSC step decrease in the Bay may contribute to some of the decreasing turbidity trend identified in this study, especially for the westernmost Delta sites.

Another factor controlling turbidity that we did not explicitly consider is the impact of flow diversions on water quality in the Delta. Water export operations significantly impact circulation patterns, flushing time, and consequently, water quality in the Delta (Monsen et al. 2007). Water exports from the pumping stations in the southern Delta alter regional circulation patterns, and changes in pumping rates can result in changes to the amount of net flow (tidal residual), in some cases, even flow direction reversal in the Central Delta (e.g., around station D28A), alternating primary source water between the Sacramento and San Joaquin Rivers (Monsen et al. 2007). The head of the Old River barrier is a rock wall in the Central Delta used to direct emigrating salmon in the spring and to amplify flows to the Stockton ship channel (near station P8) in the autumn. In the wet season, the wall is removed, and this shifts the flushing time of freshwater from days to weeks (Monsen et al. 2007). The cumulative effect of these sources of regional and seasonal variability was not considered by this study. However, we know that the rates of flow diversions and water exports in the Delta have changed and varied substantially since 1975 , and there is an increasing trend in water exports over time with the exception of drought periods 
(Lund et al. 2007). The effect of this nonstationary change in Delta hydrodynamics on turbidity is not well understood and warrants further investigation. While these changes may influence the relative effect of SAV on the turbidity trend, we think it is likely that the variability is encompassed by the upper and lower bounds of the trend effects shown in Fig. 4.

\section{Trends in SAV}

In this study, we assumed an average linear expansion rate of SAV. This was done to provide a trend estimate in the face of relatively little historic SAV cover data. Hestir et al. (2012) reported mean total SAV cover for 2004-2008 as 1817 ha. This value is similar to that reported in 1997, indicating that SAV cover may have stabilized at the system scale by the late 1990s, and perhaps an asymptotic function would better describe the trend. However, the frequency of cover estimates over the period of record and the inconsistency of cover estimation approaches make describing a nonlinear function problematic at this time. Field surveys conducted in the 1970s and reported in 1979 found one occurrence of $E$. densa with negligible cover (no patches greater than $10 \mathrm{~m}^{2}$ ), minimal occurrence and cover of $M$. spicatum (three 10-20- $\mathrm{m}^{2}$ sites with $<5 \%$ cover, and one with 6-25\%), and minimal occurrence of native Pomatogeton/Stuckenia pectinatus and native waterweed E. canadensis (Atwater et al. 1979). Field surveys conducted between 1980 and 1983 found sparse SAV occurrence (Brown and Michniuk 2007). Brown and Michniuk (2007) reported SAV present in $17 \%$ of the 204 1000-mlong reaches sampled, and most of these reaches had less than $50 \%$ SAV cover. By the late 1990s, the rapid expansion of SAV resulted in a Delta-wide SAV cover of approximately 1830 ha in 1997 as estimated from color-infrared aerial photos (Jassby and Cloern 2000). Field surveys replicating earlier work (as reported in Brown and Michniuk 2007) were conducted from 2001 to 2003, expanding sampling to 3891000 $\mathrm{m}$-long reaches. These surveys reported a substantial increase in SAV distribution and cover: $34 \%$ of the reaches had $100 \%$ SAV cover. Based on these variable reports, the reconstruction of an accurate SAV trend is not possible. The regular acquisition of high spatial resolution hyperspectral data between 2004 and 2008 enabled the first systematic SAV cover estimation approach across multiple years. Future high-resolution remote sensing acquisitions could enable a more accurate SAV trend estimation and potentially facilitate predictive modeling.

While SAV cover did not significantly vary from year to year within the turbidity station buffer zones, we know that Delta-wide SAV cover and locations of SAV vary from year to year. Light limitation from water turbidity is one habitat factor that influences SAV cover. However, there are several other factors that influence SAV distribution, expansion, and persistence, including selective herbicidal applications to control $E$. densa as prescribed by legislative action to the California Department of Boating and Waterways (Santos et al. 2009). Santos et al. (2009) reported local reductions in SAV cover between 2004 and 2007 in response to herbicide application but reported very little change in overall system-wide SAV cover $(\sim 12 \%)$. They attributed this to the high propagule pressure of Delta SAV species that enable plants to exploit year-to-year changes in habitat. High nutrient availability (Jassby and Cloern 2000) and relatively warm water temperatures throughout the year (Lucas et al. 2002) that allow overwinter survival (Santos et al. 2011) may further promote SAV persistence and propagule pressure for expansion.

The focus of this study was to separate the sediment supply effect from the SAV effect on the turbidity decline. Additional research could refine our understanding about the role of changing environmental conditions, including turbidity and associated feedbacks. Recently, Bayesian network models that encompass a large range of potential ecosystem drivers and impacts were used to identify drivers and feedbacks of seagrass biomass in an Australian estuary (Maxwell et al. 2015). That study highlighted that a Bayesian network model, when coupled with more spatially explicit input data through a GIS platform, could provide more complex spatial predictions of seagrass distribution. Future research could leverage our spatial datasets and GIS framework into an extended Bayesian network to better resolve past and future SAV distribution in the Delta.

\section{Management Implications}

The Delta has historically been considered a light-limited estuary with high nutrient loads and low phytoplankton growth (Glibert et al. 2014). Increasing water clarity has been attributed as one potential cause of multiple subsequent ecologic impacts in the Delta, including increased harmful algal blooms (Jassby et al. 2003; Glibert et al. 2014), persistent SAV distribution favoring invasive species (Santos et al. 2009, 2012), and decreased fish abundances (Sommer et al. 2007). Multiple modeling studies have identified water clarity as an important factor in determining the abundances of the declining pelagic fish species including delta smelt, longfin smelt, or striped bass (e.g., Feyrer et al. 2007; Mac Nally et al. 2010; Nobriga et al. 2008; Thomson et al. 2010). These studies identify direct and indirect effects of increasing water clarity in the Delta. Direct effects include the negative impact of increasing water clarity on juvenile delta smelt feeding (Baskerville-Bridges et al. 2004), as well as the loss of the predation refuge high turbidity provides for open water species (Ferrari et al. 2014). Indirect effects are associated with the expansion of SAV. SAV is associated with greater abundances of invasive centrarchid fish species (Brown and Michniuk 2007) and provides habitat 
for invasive predator species such as largemouth bass (Ferrari et al. 2014; Conrad et al. 2015).

Our findings highlight the importance of SAV on the water clarity trend in the Delta, where SAV may be serving as a net sediment sink. Coupled with supply limitations from the watershed and the flood control management of the Sacramento River, it is unlikely that the system will see changes in water clarity as a result of changes in the watershed (Hestir et al. 2013; Schoellhamer et al. 2013). Controlling SAV cover using spring herbicide application and an integrated vegetation management program (sensu Santos et al. 2009) may successfully reduce SAV cover and could increase turbidity and indirectly have positive effects on fish communities. However, our study encompassed 5 years of SAV cover monitoring during herbicide application, and we found no notable affect on water clarity during that time. Additional investigation is needed to understand whether SAV management affects water clarity at all, including whether there are time lags in SAV turbidity feedback loops, the role of local effects on system-wide water clarity, and subsequent indirect effects on fish communities.

\section{Conclusions}

In this study, we investigated the effect of SAV expansion on a concomitant decline in turbidity in the Sacramento-San Joaquin River Delta using long-term turbidity monitoring records and remote sensing-derived SAV maps. Our study provides, for the first time, a quantifiable estimate of the effect of the SAV expansion in the Delta on the turbidity decline (21$70 \%$ ). The adaptive traits of nonnative SAV enabled rapid expansion into open water habitat as turbidity declined due to sediment supply decreases. Positive feedbacks between SAV and water clarity further promoted SAV expansion and increasing water clarity. Our study demonstrates that SAV expansion in the Delta has had a significant effect on increasing water clarity in the Delta as a whole, beyond the local bed effects postulated by previous studies. SAV appears to be functioning as a sediment sink, promoting sediment retention and water clarity at a system-wide scale.

\begin{abstract}
Acknowledgments Funding for this research was provided by the Interagency Ecological Program through the California Department of Water Resources contract 460008137-T4 to UC Davis and through the US Bureau of Reclamation to the US Geological Survey. Additional support was provided by the California Department of Boating and Waterways agreement 03-105-114. Helpful suggestions to improve this manuscript were provided by M. J. Santos, L. Brown, N. Rybicki, P. Work, C. Ade, and two anonymous reviewers.
\end{abstract}

Open Access This article is distributed under the terms of the Creative Commons Attribution 4.0 International License (http:// creativecommons.org/licenses/by/4.0/), which permits unrestricted use, distribution, and reproduction in any medium, provided you give appropriate credit to the original author(s) and the source, provide a link to the Creative Commons license, and indicate if changes were made.

\section{References}

Atwater, B.F., S.G. Conrad, J.N. GDowden, C.W. Hedel, R.L. MacDonald, and W. Savage. 1979. History, landforms and vegetation of the estuary's tidal marshes. In San Francisco Bay: the urbanized estuary, ed. T.J. Conomos, 347-385. San Francisco: Pacific Division AAAS. 493 p.

Baskerville-Bridges, B., J.C. Lindberg, and S.I. Doroshov. 2004. The effect of light intesnity, alga concentration, and prey density on the feeding behavior of delta smelt larvae. In Early life history of fishes in the San Francisco Estuary and watershed, ed. F.L. Feyrer, L.R. Brown, and J.J. Orsi, 219-228. Bethesda: American Fisheries Society. 296 p.

Boer, W.F. 2007. Seagrass-sediment interactions, positive feedbacks and critical thresholds for occurrence: a review. Hydrobiologia 591: 524.

Brown, L.R., and D. Michniuk. 2007. Littoral fish assemblages of the alien-dominated sacramento-San Joaquin Delta, California, 1980 1983 and 2001-2003. Estuaries and Coasts 30: 186-200.

CDFA California Department of Food and Agriculture. 2013. Resource directory. Sacramento: California Department of Food and Agrilculture.

Champion, P., and C. Tanner. 2000. Seasonality of macrophytes and interaction with flow in a New Zealand lowland stream. Hydrobiologia 441: 1-12.

Cloern, J.E. 2001. Our evolving conceptual model of the coastal eutrophication problem. Marine Ecology-Progress Series 210: 223-253.

Cloern, J.E., and A.D. Jassby. 2012. Drivers of change in estuarinecoastal ecosystems: discoveries from four decades of study in San Francisco Bay. Reviews of Geophysics 50, RG4001.

Cocks, T., R. Jenssen, and A. Stewart. 1998. The HyMap airborne hyperspectral sensor: The system, calibration and performance. In 1st EARSeL workshop on imaging spectroscopy, ed. M. Schaepman, 37-42. Zurich: Remote Sensing Laboratories. 486 p.

Conrad, J.L., Bibian, A., Weinersmith, K., DeCarion, D., Young, M., Crain, P., Hestir, E.L., Santos, M.J., and Sih, A. 2015. Accepted. Invasion of Brazilian Waterweed Egeria densa facilitates expansion of an estuarine population of Largemouth Bass Micropterus salmoides. Transactions of the American Fisheries Society.

Crooks, J.A. 2002. Characterizing ecosystem-level consequences of biological invasions: the role of ecosystem engineers. Oikos 97: 153166.

Dennison, W.C., R.J. Orth, K.A. Moore, J.C. Stevenson, V. Carter, S. Kollar, P.W. Bergstrom, and R.A. Batiuk. 1993. Assessing water quality with submersed aquatic vegetation. Bioscience 43: 86-94.

Ferrari, M.O., L. Ranåker, K. Weinersmith, M. Young, A. Sih, and J.L. Conrad. 2014. Effects of turbidity and an invasive waterweed on predation by introduced largemouth bass. Environmental Biology of Fishes 97: 79-90.

Feyrer, F., M.L. Nobriga, and T.R. Sommer. 2007. Multi-decadal trends for three declining fish species: habitat patterns and mechanisms in the San Francisco Estuary. Environmental Biology of Fishes 67: 277-288.

Findlay, S.E.G., D.L. Strayer, S.D. Smith, and N. Curri. 2014. Magnitude and Patterns of Change in Submerged Aquatic Vegetation of the Tidal Freshwater Hudson River. Estuaries and Coasts 1-10.

Ganju, N.K., D.H. Schoellhamer, M.C. Murrell, J.W. Gartner, and S.A. Wright. 2007. Constancy of the relation between floc size and density in San Francisco Bay. In Estuarine and coastal fine sediment dynamics, ed. J. Maa, L.P. Sanford, and D.H. Schoellhamer, 75-91. Amsterdam: Elsevier Science. 536 p.

Glibert, P.M., R.C. Dugdale, F. Wilkerson, A.E. Parker, J. Alexander, E. Antell, S. Blaser, A. Johnson, J. Lee, T. Lee, S. Murasko, and S. Strong. 2014. Major-but rare-spring blooms in 2014 in San Francisco Bay Delta, California, a result of the long-term drought, 
increased residence time, and altered nutrient loads and forms. Journal of Experimental Marine Biology and Ecology 460: 8-18.

Helsel, D.R., and R.M. Hirsch. 1992. Statistical methods in water resources. Studies in Environmental Science 49: 76.

Hestir, E.L. 2010. Trends in Estuarine Water Quality and Submerged Aquatic Vegetation Invasion. PhD dissertation. Department of Land, Air and Water Resources, University of California Davis, $139 \mathrm{p}$.

Hestir, E.L., J.A. Greenberg, and S.L. Ustin. 2012. Classification trees for aquatic vegetation community prediction from imaging spectroscopy. IEEE Journal of Selected Topics in Earth Observations and Remote Sensing 5: 1572-1584.

Hestir, E.L., D.H. Schoellhamer, T. Morgan-King, and S.L. Ustin. 2013. A step decrease in sediment concentration in a highly modified tidal river delta following the 1983 El Niño floods. Marine Geology 345: 304-313.

Jassby, A.D. 2008. Phytoplankton in the upper San Francisco estuary: recent biomass trends, their causes, and their trophic significance. San Francisco Estuary and Watershed Science 6.

Jassby, A.D., and J.E. Cloern. 2000. Organic matter sources and rehabilitation of the Sacramento-San Joaquin Delta (California, USA). Aquatic Conservation: Marine and Freshwater Ecosystems 10.

Jassby, A.D., J.E. Cloern, and B.E. Cole. 2002. Annual primary production: patterns and mechanisms of change in a nutrient-rich tidal ecosystem. Limnology and Oceanography 47: 698-712.

Jassby, A.D., J.E. Cloern, and A. Mueller-Solger. 2003. Phytoplankton fuels delta food Web. California Agriculture 57: 104-109.

Kuivila, K.M., and C.G. Foe. 1995. Concentrations, transport, and biological effects of dormant spray pesticides in the San Francisco Estuary, California. Environmental Toxicology and Chemistry 14: $1141-1150$

Liu, X., Y. Zhang, Y. Yin, M. Wang, and B. Qin. 2013. Wind and submerged aquatic vegetation influence bio-optical properties in large shallow Lake Taihu, China. Journal of Geophysical Research: Biogeosciences 118: 713-727.

Lucas, L.V., J.E. Cloern, J.K. Thompson, and N.E. Monsen. 2002. Functional variability of habitats within the Sacramento-San Joaquin Delta: restoration implications. Ecological Applications 12: $1528-1547$.

Lund, J., E. Hanak, W. Fleenor, R. Howitt, J. Mount, and P. Moyle. 2007. Envisioning futures for the Sacramento-San Joaquin delta. San Francisco: Public Policy Institute of California. 325 p.

Mac Nally, R., J.R. Thomson, W.J. Kimmerer, F. Feyrer, K.B. Newman, A. Sih, W.A. Bennet, L. Brown, E. Fleishman, S.D. Culberson, and G. Castillo. 2010. Analysis of pelagic species decline in the upper San Francisco Estuary using multivariate autoregressive modeling (MAR). Ecological Applications 20: 1417-1430.

Madsen, J.D., P.A. Chambers, W.F. James, E.W. Koch, and D.F. Westlake. 2001. The interaction between water movement, sediment dynamics and submersed macrophytes. Hydrobiologia 44: 71-84.

Marineau, M.D. 2015. Written communication, U.S. Geological Survey California Water Science Center.

Maxwell, P.S., K.A. Pitt, A.D. Olds, D. Rissik, and R.M. Connolly. 2015. Identifying habitats at risk: simple models can reveal complex ecosystem dynamics. Ecological Applications 25: 573-587.

Monsen, N.E., Cloern, J.E., and J.R. Burau. 2007. Effects of flow diversions on water and habitat quality: Examples from California's highly manipulated Sacramento-San Joaquin Delta. San Francisco Estuary and Watershed Science 5: Article 2.

Monserud, R.A., and R. Leemans. 1992. Comparing global vegetation maps with the Kappa statistic. Ecological Modelling 62: 275-293.

Moore, K., E. Shields, D. Parrish, and R. Orth. 2012. Eelgrass survival in two contrasting systems: role of turbidity and summer water temperatures. Marine Ecology Progress Series 448: 247-258.

Nichols, F.H., J.E. Cloern, S.N. Luoma, and D.H. Peterson. 1986. The modification of an estuary. Science 231: 567-573.
Nobriga, M.L., F. Feyrer, R.D. Baxter, and M. Chotkowski. 2005. Fish community ecology in an altered river delta: spatial patterns in species composition, life history strategies, and biomass. Estuaries 28: 776-785.

Nobriga, M., T.R. Sommer, F. Feyrer, and K. Flemming. 2008. Long-term trends in summertime habitat suitability for delta smelt, Hypomesus transpacificus. San Francisco Estuary and Watershed Science 6: 1.

Orth, R.J., T.J.B. Carruthers, W.C. Dennison, C.M. Duarte, J.W. Fourqurean, K.L. Heck, A.R. Hughes, G.A. Kendrick, W.J. Kenworthy, S. Olyarnik, F.T. Short, M. Waycott, and S.L. Williams. 2006. A global crisis for seagrass ecosystems. Bioscience 56: 987-996.

Sand-Jensen, K., and J. Borum. 1991. Interactions among phytoplankton, periphyton, and macrophytes in temperate freshwaters and estuaries. Aquatic Botany 41: 137-175.

Sand-Jensen, K., and J.R. Mebus. 1996. Fine-scale patterns of water velocity within macrophytes patches in streams. Oikos 76: 169-180.

Santos, M.J., S. Khanna, E.L. Hestir, M.E. Andrew, S. Rajapakse, J.A. Greenberg, L.W. Anderson, and S.L. Ustin. 2009. Use of hyperspectral remote sensing to evaluate efficacy of aquatic plant management. Invasive Plant Science and Management 2: $216-229$

Santos, M., L. Anderson, and S. Ustin. 2011. Effects of invasive species on plant communities: an example using submersed aquatic plants at the regional scale. Biological Invasions 13: 443-457.

Santos, M.J., E.L. Hestir, S. Khanna, and S.L. Ustin. 2012. Image spectroscopy and stable isotopes elucidate functional dissimilarity between native and nonnative plant species in the aquatic environment. New Phytologist 193: 683-695.

Scheffer, M., and E.H. van Nes. 2007. Shallow lakes theory revisited: various alternative regimes driven by climate, nutrients, depth and lake size. Hydrobiologia 584: 455-466.

Scheffer, M., S.H. Hosper, M.L. Meijer, B. Moss, and E. Jeppesen. 1993. Alternative equilibria in shallow lakes. Trends in Ecology \& Evolution 8: 275-279.

Schertz, T.L., R.B. Alexander, and D.J. Ohe. 1991. The computer program Estimate TREND (ESTREND), a system for the detection of trends in water-quality data., 72. Reston, VA: U.S. Geological Survey.

Schoellhamer, D.H. 2011. Sudden clearing of estuarine waters upon crossing the threshold from transport to supply regulation of sediment transport as an erodible sediment pool is depleted: San Francisco Bay, 1999. Estuaries and Coasts 34: 885-899.

Schoellhamer, D.H., T.E. Mumley, and J.E. Leatherbarrow. 2007. Suspended sediments and sediment-associated contaminants in the San Francisco Bay. Environmental Research 105: 119-131.

Schoellhamer, D.H., S.A. Wright, and J.Z. Drexler. 2012. A conceptual model of sedimentation in the Sacramento-San Joaquin Delta. San Francisco Estuary and Watershed Science 10: jmie_sfews 11152 .

Schoellhamer, D.H., S.A. Wright, and J.Z. Drexler. 2013. Adjustment of the San Francisco estuary and watershed to decreasing sediment supply in the 20th century. Marine Geology 345: 63-71.

Service, F. 2007. Delta blues, California style. Science 317: 442-444.

Sommer, T.R., and F. Meja. 2013. A synthesis of delta smelt habitat in the upper San Francisco estuary. San Francisco Estuary and Watershed Science 11: jmie sfews 12672.

Sommer, T.R., C. Armor, R.D. Baxter, R. Breuer, L. Brown, M. Chotkowski, S. Culberson, F. Feyrer, M. Gingras, B. Herbold, W. Kimmerer, A. Mueller-Solger, M.L. Nobriga, and K. Souza. 2007. The collapse of pelagic fishes in the upper San Francisco estuary. Fisheries 32: 270-277.

Thomson, J.R., W.J. Kimmerer, L.R. Brown, K.B. Newman, R. Mac Nally, W.A. Bennet, F. Feyrer, and E. Fleishman. 2010. Bayesian change point analysis of abundance trends for pelagic fishes in the upper San Francisco Estuary. Ecological Applications 20: 1431-1448. 
Ustin, S.L., M.J. Santos, E.L. Hestir, S. Khanna, A. Casas, and J. Greenberg. 2014. Developing capacity to monitori climate change impacts in Mediterranean estuaries. Evolutionary Ecology Research 16: $529-550$.

Vanderstukken, M., S.A.J. Declerck, E. Decaestecker, and K. Muylaert. 2014. Long-term allelopathic control of phytoplankton by the submerged macrophyte Elodea nuttallii. Freshwater Biology 59: 930 941.

Waycott, M., C.M. Duarte, T.J.B. Carruthers, R.J. Orth, W.C. Dennison, S. Olyarnik, A. Calladine, J.W. Fourqurean, K.L. Heck, A.R. Hughes, G.A. Kendrick, W.J. Kenworthy, F.T. Short, and S.L.
Williams. 2009. Accelerating loss of seagrasses across the globe threatens coastal ecosystems. Proceedings of the National Academy of Sciences 106: 12377-12381.

Wright, S.A., and D.H. Schoellhamer. 2004. Trends in the sediment yield of the Sacramento River, CA, 1975-2001. San Francisco Estuary and Watershed Science 2: 2.

Wright, S.A., and D.H. Schoellhamer. 2005. Estimating sediment budgets at the interface between rivers and estuaries with application to the Sacramento-San Joaquin River Delta. Water Resources Research 41, W09428. 